\title{
Increased Seasonal Variation in Serotonin Transporter Binding in Seasonal Affective Disorder
}

\author{
Andrea E Tyrer', Robert D Levitan', Sylvain Houle', Alan A Wilson', José N Nobrega ${ }^{1,2}$ and Jeffrey H Meyer,,I \\ 'Departments of Psychiatry, Pharmacology and Toxicology, CAMH Research Imaging Centre, Centre for Addiction and Mental Health, Campbell \\ Family Mental Health Research Institute, and Institute of Medical Sciences, University of Toronto, Toronto, ON, Canada; ${ }^{2}$ Behavioural Neurobiology \\ Laboratory, Departments of Psychiatry, Pharmacology and Toxicology, and Psychology, Campbell Family Mental Health Research Institute, \\ University of Toronto, Toronto, ON, Canada
}

\begin{abstract}
Seasonal affective disorder (SAD) is highly prevalent with rates of I-6\% and greater prevalence at more extreme latitudes; however, there are almost no direct brain investigations of this disorder. In health, serotonin transporter binding potential (5-HTT BP $\mathrm{ND})$, an index of $5-\mathrm{HTT}$ levels, is greater throughout the brain in fall-winter compared with spring-summer. We hypothesized that in SAD, this seasonal variation would be greater in brain regions containing structures that regulate affect such as the prefrontal and anterior cingulate cortices (PFC and ACC). Furthermore, given the dimensional nature of SAD symptoms, it was hypothesized that seasonal fluctuation of 5-HTT $\mathrm{BP}_{\mathrm{ND}}$ in the PFC and ACC would be greatest in severe SAD. Twenty SAD and twenty healthy participants underwent [ ' ${ }^{1}$ ]DASB positron emission tomography scans in summer and winter to measure seasonal variation in [ [ $\mathrm{C}] \mathrm{DASB} 5-\mathrm{HTT}$ BP $\mathrm{ND}$. Seasonal increases in [ ' ' C]DASB 5-HTT BP ND were greater in SAD compared with healthy in the PFC and ACC, primarily due to differences between severe SAD and healthy (severe SAD vs healthy; Mann-Whitney $U, U=42.5$ and 37.0, $p=0.005$ and 0.003 , respectively; greater magnitude in severe SAD of 35.10 and $14.23 \%$, respectively), with similar findings observed in other regions $(U=40.0-62.0$, $p=0.004-0.048$; greater magnitude in severe SAD of 13.16-17.49\%). To our knowledge, this is the first brain biomarker identified in SAD. This creates a new opportunity for phase 0 studies to target this phenotype and optimize novel prevention/treatment strategies for SAD.

Neuropsychopharmacology (2016) 4I, 2447-2454; doi: I0.1038/npp.2016.54; published online 4 May 2016
\end{abstract}

\section{INTRODUCTION}

Seasonal affective disorder (SAD), a subtype of major depressive disorder (MDD) characterized by recurrent winter major depressive episodes (MDEs) with full remission in spring-summer, poses a heavy burden: among the subtypes of MDD, it has the highest frequency of MDEs being almost yearly, and $40 \%$ of cases progress to nonseasonal MDEs (Faedda et al, 1993; Rosenthal et al, 1984a; Schwartz et al, 1996). The annual prevalence of SAD is typically $1-6 \%$, with the highest rates occurring at more extreme latitudes (Magnusson, 2000). Although information about SAD is accumulating, a critical gap is the lack of direct brain investigations of this illness. Biological abnormalities of SAD include, in winter, increased duration and/or delay of nocturnal melatonin secretion, blunted norepinephrine, cortisol, and prolactin response to challenge with the non-selective serotonin receptor agonist $\mathrm{m}$-CPP, and decreased rod sensitivity to light as measured by flash

\footnotetext{
* Correspondence: Dr JH Meyer, CAMH Research Imaging Centre, Campbell Family Mental Health Research Institute, Centre for Addiction and Mental Health, 250 College Street, Toronto, ON M5TI R8, Canada, Tel: + | 416535850 I × 34007, Fax: + I 416979 4656,

E-mail: jeff.meyer@camhpet.ca

Received 27 January 2016; revised 21 March 2016; accepted 25 March 2016; accepted article preview online 18 April 2016
}

electroretinography (Lavoie et al, 2009; Levitan et al, 1998; Schwartz et al, 1997; Wehr et al, 2001). Vulnerability markers include altered polymorphism frequencies for clock genes NPAS and PER3, as well as a variable number tandem repeat on exon 3 of the DRD4 gene (Johansson et al, 2003; Levitan et al, 2006). Given the substantial burden of SAD, its high prevalence, and the lack of knowledge regarding the brain phenotypes of this disorder, there is a clear need to identify neurochemical and neuropathological markers in the central nervous system of SAD.

One strategy for selecting a target to investigate in SAD is to choose a functionally relevant brain marker that is sensitive to seasonal effects in healthy humans. Brain markers influenced by season in health include greater striatal L-Dopa uptake in the fall-winter, decreased $5-\mathrm{HT}_{1 \mathrm{~A}}$ receptor binding in limbic regions in winter, altered wholebrain serotonin turnover, and greater $5-\mathrm{HTT}_{\mathrm{BP}} \mathrm{ND}$, an index related to 5-HTT density, in the fall-winter as compared with spring-summer (Buchert et al, 2006; Eisenberg et al, 2010; Kalbitzer et al, 2010; Lambert et al, 2002; Ruhé et al, 2009; Spindelegger et al, 2012; Praschak-Rieder et al, 2008). In regards to seasonal variation of $5-\mathrm{HTT} \mathrm{BP}_{\mathrm{ND}}$, neuroimaging studies of reasonably large sample size consistently report this finding in a high proportion of brain regions sampled: a $\left[{ }^{11} \mathrm{C}\right] \mathrm{DASB}$ PET study of 88 subjects at Toronto, Canada, found seasonal variation in $\left[{ }^{11} \mathrm{C}\right] \mathrm{DASB}$-HTT $\mathrm{BP}_{\mathrm{ND}}$ across 
all examined brain regions including the prefrontal cortex, anterior cingulate cortex (PFC and ACC, respectively), and hippocampus (Praschak-Rieder et al, 2008). Similarly, an independent $\left[{ }^{11} \mathrm{C}\right] \mathrm{DASB}$ PET study of 57 participants at Copenhagen, Denmark found evidence of seasonal fluctuation in $\left[{ }^{11} \mathrm{C}\right] \mathrm{DASB} 5$-HTT $\mathrm{BP}_{\mathrm{ND}}$ in 3 of 4 brain regions with significant change in the caudate and putamen, a trend in the thalamus and no effect in the midbrain (Kalbitzer et al, 2010). Two additional studies in Amsterdam, Netherlands and Hamberg Germany, applying $\left[{ }^{123} \mathrm{I}\right] \beta$-CIT SPECT and $\left[{ }^{11} \mathrm{C}\right] \mathrm{McN} 5652 \mathrm{PET}$, respectively, investigated the thalamus and midbrain and both found seasonal variation in 5-HTT $\mathrm{BP}_{\mathrm{ND}}$ in the midbrain (the Amsterdam study included both healthy and non-SAD MDD patients) (Buchert et al, 2006; Ruhé et al, 2009). The 5-HTT is also an important target for controlling affect given that polymorphisms in the 5-HTT promoter are associated with risk toward MDD, medications that affect the 5-HTT influence both cognitive recall of emotionally valent material and negative cognitive interpretations of life events; and that overexpression of 5-HTT in regions controlling affect are associated with depressive behaviors in rodents (Caspi et al, 2010; Harmer et al, 2004; Line et al, 2014; Meyer et al, 2003; Mouri et al, 2012).

Given the consistency of seasonal change in 5-HTT $\mathrm{BP}_{\mathrm{ND}}$ in health and the importance of the role of 5-HTT in affect regulation, the aim of the present study was to investigate seasonal fluctuation in $\left[{ }^{11} \mathrm{C}\right] \mathrm{DASB}$ 5-HTT $\mathrm{BP}_{\mathrm{ND}}$ in SAD as compared to health. We prioritized the PFC and ACC as these regions had considerable seasonal variation in previous study, contain structures with key roles in mood regulation and cognitive processing of emotion, and are the regions for which 5-HTT overexpression is associated with depressive behaviors (Line et al, 2014; Mouri et al, 2012; PraschakRieder et al, 2008; Ressler and Mayberg, 2007).

The first hypothesis was that the magnitude of seasonal variation in $\left[{ }^{11} \mathrm{C}\right] \mathrm{DASB} 5$-HTT $\mathrm{BP}_{\mathrm{ND}}$ in the $\mathrm{PFC}$ and ACC would be greater in SAD as compared to health. The second hypothesis was that seasonal variation in $\left[{ }^{11} \mathrm{C}\right] \mathrm{DASB} 5$-HTT $\mathrm{BP}_{\mathrm{ND}}$ in the PFC and ACC would be associated with severity of SAD symptoms. The rationale for the second hypothesis is that SAD is well known to be a dimensional illness with a continuous distribution within health (such that $25 \%$ of healthy individuals experience mild seasonal symptoms) through to SAD of moderate to high severity (Bartko and Kasper, 1989; Kasper et al, 1989; Rohan et al, 2011); and in MDD the magnitude of brain biomarker abnormalities is often correlated with severity, reflecting that MDD is a complex neuropsychiatric illness for which any individual pathology is more likely to present when MDD is more severe (Chiuccariello et al, 2014; Deschwanden et al, 2011; Fujita et al, 2012; Meyer, 2012; Sanacora et al, 2004; Setiawan et al, 2015).

\section{MATERIALS AND METHODS}

\section{Study Participants}

Twenty SAD participants ( 14 women and 6 men; mean [SD] age: 31.3 [4.8] years; age range: $24-39$ ) and twenty healthy volunteers (13 women and 7 men; mean [SD] age: 30.5 [4.2] years; age range: 24-39) were recruited from the Greater Toronto Area between June 2012 and July 2015. Healthy subjects were age-matched to SAD subjects within 3 years. Demographics are listed in Table 1.

Criteria for all included being age 18-40, non-smoking and in good physical health, no history of alcohol or substance abuse, no antidepressant use within the past 6 months, and no use of prescription medications or herbal supplements within the past 2 months. In addition, as light exposure has been found to reduce $\left[{ }^{11} \mathrm{C}\right] \mathrm{DASB}$ 5-HTT $\mathrm{BP}_{\mathrm{ND}}$ during the winter months and $\left[{ }^{11} \mathrm{C}\right] \mathrm{DASB} 5-\mathrm{HTT} \mathrm{BP}_{\mathrm{ND}}$ has been shown to be inversely correlated with duration of daily sunshine, both use of light therapy within the past 3 months and travel to more southern latitudes during the study period were exclusionary (Harrison et al, 2015; Praschak-Rieder et al, 2008). Exclusion criteria for female subjects included the use of oral contraceptives, current pregnancy, postpartum or recent abortion (within one year), and in perimenopause or menopause. Subjects were asked not to take over the counter medications 1 week before scanning, to avoid alcohol 4 days before scanning, and not to consume caffeinated beverages within 2 days of the PET scan. In addition, lifetime history of Axis I or Axis II disorders was exclusionary for healthy subjects, and comorbid Axis I or Axis II disorders were exclusionary for SAD subjects. Screening instruments

Table I Demographic Characteristics

\begin{tabular}{|c|c|c|c|}
\hline & $\operatorname{SAD}(n=20)$ & Healthy $(n=20)$ & Statistical comparison \\
\hline Age, mean (SD) & $31.3(4.8)$ & $30.5(4.2)$ & $t_{38}=0.56(p=0.58)$ \\
\hline Female to male ratio & $14: 6$ & $13: 7$ & $\chi_{(1)}^{2}=0.11 \quad(p=0.74)^{a}$ \\
\hline Body mass index (SD) & $24.6(3.5)$ & $23.2(3.2)$ & $t_{38}=1.37(p=0.18)$ \\
\hline Years in climatic area & $22.3(12.2)$ & $22.2(11.4)$ & $t_{38}=0.013(p=0.99)$ \\
\hline Age of SAD onset & $21.9(5.4)$ & N/A & $N / A$ \\
\hline Winter SIGH-SAD (HDRS-29) & $26.0(9.93)$ & $1.56(1.9)$ & $t_{20}=10.79(p<0.000 \mid)^{c}$ \\
\hline Summer SIGH-SAD (HDRS-29) & $2.7(3.05)$ & $1.3(1.8)$ & $t_{30}=1.78(p=0.09)^{c}$ \\
\hline SPAQ (Global Seasonality Score) & $16.8(3.2)$ & $2.1(1.7)$ & $t_{28}=18.15(p<0.000 \mid)^{c}$ \\
\hline
\end{tabular}

${ }^{a}$ Chi-Square test for association. ${ }^{b}$ No. of seasonal MDEs consistent with reports from the literature (Lam et al, 2006; Modell et al, 2005). 'Welch's independent samples $t$-test for unequal variances. 
included the Structured Clinical Interview for DSM-IV-TR (SCID-I/II); and all SAD subjects received a consultation with a psychiatrist (JHM or RDL) to verify diagnosis. Urine drug screening was performed at initial assessment and on each PET scanning day to rule out recent drug and medication use. Urine toxicology was performed using gas chromatography-mass spectrometry (GC-MS) at the CAMH clinical laboratory (drug screening sensitive to ethanol, drugs of abuse, all classes of antidepressants, antipsychotics, anticonvulsants, benzodiazepines, narcotics, NSAIDs, anthelmintics, statins, $\beta$-blockers, muscle relaxants, and anti-allergy medications).

Participants also completed the Seasonal Pattern Assessment Questionnaire (SPAQ) from which a summed global seasonality score (SPAQ GSS) was calculated to determine the degree of seasonality (ie, seasonal change in sleep, mood, energy, appetite, weight, and social activity) (Rosenthal et al, $1984 \mathrm{~b})$. The SPAQ was administered in randomized order in accordance with the season in which subjects were scanned (summer: 10 healthy, $8 \mathrm{SAD}$; winter: 10 healthy, $\left.12 \mathrm{SAD} ; \chi_{(1)}^{2}=0.40, p=0.53\right)$. Subjects were defined categorically as healthy (with no seasonality) for SPAQ scores below 12, moderate SAD for scores between 12 and 16, and severe SAD for scores equal to or greater than 16 (Bartko and Kasper, 1989). All healthy participants had SPAQ scores of less than 7 (mean [SD]: 2.1 [1.7], range 0-6, Table 1). On each scan day, the Structured Interview Guide for the Hamilton Depression Rating Scale with Seasonal Affective Disorder Supplement (SIGH-SAD) was also administered. For each participant, written informed consent was obtained after the procedures were fully explained. The study and recruitment procedures were approved by the Research Ethics Board for Human Subjects at the Centre for Addiction and Mental Health, University of Toronto.

\section{Scanning}

All participants underwent two $\left[{ }^{11} \mathrm{C}\right] \mathrm{DASB}$ PET and MRI scans: one in spring-summer and the other in fall-winter, in randomized order, to measure the seasonal percent change in $\left[{ }^{11} \mathrm{C}\right]$ DASB 5-HTT $\mathrm{BP}_{\mathrm{ND}}$. Scan dates of healthy controls were matched to SAD participants within 4 weeks. To minimize any potential effects of circadian rhythm, all scans were scheduled in the morning and took place at either $0930 \mathrm{~h}$ or $1130 \mathrm{~h}$. All participants were non-smoking and on each PET scan day underwent laboratory tests (plasma sampling for cotinine, calcium and thyroid hormones, complete blood cell count) to verify non-smoking status and ensure physical health.

Synthesis of $\left[{ }^{11} \mathrm{C}\right] \mathrm{DASB}$ has been described previously (Ginovart et al, 2001; Wilson et al, 2000). Briefly, [ $\left.{ }^{11} \mathrm{C}\right]-\mathrm{CH} 3$ was trapped in a high-performance liquid chromatography sample loop coated with a solution of the $N$-normethyl precursor $(1 \mathrm{mg})$ in dimethylformamide $(80 \mu \mathrm{l})$. After $5 \mathrm{~min}$ at ambient temperature, the contents of the sample loop were injected onto a reverse-phase high-performance liquid chromatography column, and the fraction containing the product was collected, evaporated to dryness, formulated in saline, and filtered through a $0.2-\mu$ filter. Before each scan, an intravenous bolus of $10 \mathrm{mCi}(370 \mathrm{MBq})$ of $\left[{ }^{11} \mathrm{C}\right] \mathrm{DASB}$ was injected. The $\left[{ }^{11} \mathrm{C}\right] \mathrm{DASB}$ was of high radiochemical purity $(98.10 \pm 5.16 \%)$ and high specific activity $(65.62 \pm 26.36 \mathrm{GBq} /$ $\mu \mathrm{mol})$ at the time of injection. PET images were obtained using a high-resolution PET/CT Siemens-Biograph HiRez XVI scanner (81 axial sections of $2 \mathrm{~mm}$; Siemens Molecular Imaging, Knoxville, TN). The emission scan was reconstructed in 15 frames of $1 \mathrm{~min}$, followed by 15 frames of $5 \mathrm{~min}$, totaling to a scan duration of $90 \mathrm{~min}$ in length. The images were corrected for attenuation using a germanium 68-labeled transmission scan and reconstructed using 2D filtered back projection algorithms with a ramp filter. Subsequent to the initial PET scan, each participant also underwent a magnetic resonance imaging scan (GE 3.0-T scanner, fast spin echo -XL sequence, proton densityweighted image, $\mathrm{x}, \mathrm{y}$, and $\mathrm{z}$ voxel dimensions; 0.37, 0.37, and $0.90 \mathrm{~mm}$, GE Medical Systems, Milwaukee, WI).

Regions of interest (ROIs) on the MRI were determined using a semi-automated method in which regions of a template MRI are transformed onto the individual MRI based on a series of transformations and deformations that matched the template image to the individual co-registered MRI, as well as segmentation of the individual MRI to select gray-matter voxels as previously described (Meyer et al, 2009; Rusjan et al, 2006). ROIs on the MRI were subsequently located on the PET image using the rigid body transformations from co-registration of the MRI to PET image via a mutual information algorithm. ROIs included the prefrontal cortex, anterior cingulate cortex, ventral striatum, dorsal caudate, dorsal putamen, thalamus, hippocampus, midbrain, and cerebellar cortex. The location of the ROIs was verified by visual assessment of their display on the integral $\left[{ }^{11} \mathrm{C}\right] \mathrm{DASB}$ PET image. The cerebellar cortex reference region was defined as the posterior half of the cerebellar cortex, excluding the vermis and cerebellar white matter. Reference tissue methods have been validated for $\left[{ }^{11} \mathrm{C}\right] \mathrm{DASB}$ to calculate $\left[{ }^{11} \mathrm{C}\right] \mathrm{DASB}$ 5-HTT BP ${ }_{\mathrm{ND}}$ (Ginovart et al, 2001; Ichise et al, 2003). We applied the non-invasive Logan method, which has a modest underestimate, but the advantage of having the lowest coefficient of variation (ie, standard deviation/mean) of calculated $\mathrm{BP}_{\mathrm{ND}}$ values (Logan et al, 1996). An additional analysis was conducted using the simplified reference tissue method 2 (SRTM2), which has a negligible underestimate but a higher coefficient of variation (Wu and Carson, 2002). Test-retest variability of $\left[{ }^{11} \mathrm{C}\right] \mathrm{DASB}$ 5-HTT $\mathrm{BP}_{\mathrm{ND}}$ values using the non-invasive Logan method have been reported to have a mean regional change of $0 \%$ with a standard deviation of $\pm 4.75 \%$ in the prefrontal cortex, $\pm 3.7 \%$ in the anterior cingulate cortex, $\pm 1.6 \%$ in the bilateral caudate, $\pm 2.6 \%$ in the bilateral putamen, $\pm 2.5 \%$ in the thalamus, and $\pm 0.3 \%$ in the midbrain/superior raphe nuclei, with similar results obtained using the SRTM2 method (Praschak-Rieder et al, 2005).

\section{Statistical Analyses}

Seasonal percent change in $\left[{ }^{11} \mathrm{C}\right] \mathrm{DASB} 5$-HTT $\mathrm{BP}_{\mathrm{ND}}(\% \Delta$ $\left[{ }^{11} \mathrm{C}\right] \mathrm{DASB} 5$-HTT $\mathrm{BP}_{\mathrm{ND}}$ ) was calculated in each region for each subject [(winter $\left[{ }^{11} \mathrm{C}\right] \mathrm{DASB}$ 5-HTT $\mathrm{BP}_{\mathrm{ND}}$-summer $\left[{ }^{11} \mathrm{C}\right] \mathrm{DASB}$ 5-HTT $\left.\mathrm{BP}_{\mathrm{ND}}\right) /$ summer $\quad\left[{ }^{11} \mathrm{C}\right] \mathrm{DASB}$ 5-HTT $\left.\mathrm{BP}_{\mathrm{ND}}\right)$ ] and, as one value pertaining to a severe $\mathrm{SAD}$ case was slightly outside the normal distribution, non-parametric tests were used for all statistical analyses. The \% $\Delta\left[{ }^{11} \mathrm{C}\right]$ DASB 5-HTT $\mathrm{BP}_{\mathrm{ND}}$ in the PFC and ACC was compared between $\mathrm{SAD}$ and healthy groups using the Mann-Whitney $U$-test. To assess the relationship of $\% \Delta\left[{ }^{11} \mathrm{C}\right] \mathrm{DASB} 5$-HTT 
Table 2 Group Differences in Seasonal Change in 5-HTT BP ND

\begin{tabular}{lcc}
\hline Brain region & \multicolumn{2}{c}{ Mann-Whitney U-test } \\
\cline { 2 - 3 } & \multicolumn{2}{c}{ SAD vs Healthy } \\
\cline { 2 - 3 } & $\mathbf{U}^{\mathbf{a}}$ & $\mathbf{p}$-Value \\
\hline Prefrontal cortex & 126.5 & 0.046 \\
Anterior cingulate cortex & 114.0 & 0.02 \\
Dorsal putamen & 140.0 & 0.10 \\
Thalamus & 147.0 & 0.15 \\
Dorsal caudate & 154.0 & 0.22 \\
Ventral striatum & 154.0 & 0.21 \\
Midbrain & 96.0 & 0.005 \\
Hippocampus & 153.0 & 0.20
\end{tabular}

5-HTT BP ${ }_{N D}$, serotonin transporter binding potential (non-displaceable); MannWhitney $U$, non-parametric equivalent of an independent samples t-test.

aann-Whitney U-test statistic.

$\mathrm{BP}_{\mathrm{ND}}$ to severity, the primary method was to categorize SAD into two groups, moderate and severe, applying a cutoff of greater than 16 on the SPAQ as previously described (Bartko and Kasper, 1989). To determine whether a difference was present among healthy, moderate $\mathrm{SAD}$, and severe $\mathrm{SAD}$ groups, the Kruskal-Wallis $H$-test was applied to assess $\% \Delta$ $\left[{ }^{11} \mathrm{C}\right] \mathrm{DASB} 5-\mathrm{HTT} \mathrm{BP}_{\mathrm{ND}}$ in the PFC and ACC, and then the Mann-Whitney $U$-test was used to compare healthy with severe $\mathrm{SAD}$. As a secondary approach, all analyses were applied in the other ROIs.

As an additional analysis, the effect of severity of SAD upon seasonal change in $\left[{ }^{11} \mathrm{C}\right] \mathrm{DASB} 5-\mathrm{HTT} \mathrm{BP}_{\mathrm{ND}}$ was investigated. Seasonal change in $\left[{ }^{11} \mathrm{C}\right] \mathrm{DASB} 5-\mathrm{HTT} \mathrm{BP}_{\mathrm{ND}}\left(\Delta\left[{ }^{11} \mathrm{C}\right] \mathrm{DASB} 5-\right.$ $\mathrm{HTT} \mathrm{BP}_{\mathrm{ND}}$ ) was calculated for each participant (winter $\left[{ }^{11} \mathrm{C}\right]$ DASB 5-HTT BP $\mathrm{ND}$-summer $\left[{ }^{11} \mathrm{C}\right] \mathrm{DASB}$ 5-HTT BP $\left.{ }_{\mathrm{ND}}\right)$. To determine whether a difference was present among healthy, moderate $\mathrm{SAD}$, and severe SAD groups, the Kruskal-Wallis $H$-test was applied to assess $\Delta\left[{ }^{11} \mathrm{C}\right] \mathrm{DASB} 5-\mathrm{HTT} \mathrm{BP}_{\mathrm{ND}}$ in the PFC and ACC and other examined regions, followed by the Mann-Whitney $U$-test to compare healthy with severe and moderate SAD groups. The Kruskal-Wallis $H$-test was also used to determine whether $\left[{ }^{11} \mathrm{C}\right] \mathrm{DASB} 5$-HTT $\mathrm{BP}_{\mathrm{ND}}$ values differed across groups in winter and in summer.

Further assessments of the relationship to severity of symptoms were to determine the Spearman correlation coefficients between $\% \Delta\left[{ }^{11} \mathrm{C}\right] \mathrm{DASB} 5$-HTT $\mathrm{BP}_{\mathrm{ND}}$ in the PFC and ACC and seasonal depressive symptoms, as measured by the SPAQ. These correlations were also determined for other ROIs. Finally, as an exploratory analysis, Spearman correlation coefficients were used to assess the relationship between $\Delta\left[{ }^{11} \mathrm{C}\right] \mathrm{DASB}$ 5-HTT $\mathrm{BP}_{\mathrm{ND}}$ and seasonal depressive symptoms in all brain regions assayed.

\section{RESULTS}

\section{Effect of SAD and Severity Category on $\% \Delta\left[{ }^{11} \mathrm{C}\right] \mathrm{DASB}$ 5-HTT BP $\mathrm{ND}$}

Seasonal \% $\Delta\left[{ }^{11} \mathrm{C}\right] \mathrm{DASB}$ 5-HTT $\mathrm{BP}_{\mathrm{ND}}$ was greater in $\mathrm{SAD}$ as compared to health in the PFC and ACC
(Mann-Whitney $U, U=126.5$ and 114.0, $p=0.046$ and 0.02 , respectively, Table 2). However, the strongest finding was a main effect of group (healthy, moderate SAD, and severe SAD) upon seasonal fluctuation in $\left[{ }^{11} \mathrm{C}\right] \mathrm{DASB}$ 5-HTT $\mathrm{BP}_{\mathrm{ND}}$ in the PFC and ACC (Kruskal-Wallis $H$-test, $\chi_{(2)}^{2}=8.82, p=0.01$ and $\chi_{(2)}^{2}=9.62, p=0.008$, respectively, Figure 1 and Table 3$)$. Similar findings were present across other ROIs $\left(\chi_{(2)}^{2}=7.01-10.45, p=0.005-0.03\right.$, Figure 1 and Table 3), excepting the hippocampus in which a trend-level effect was observed $\left(\chi_{(2)}^{2}=5.26, p=0.07\right.$; Figure 1 and Table 3$)$. These findings were primarily explained by greater seasonal \% $\Delta\left[{ }^{11} \mathrm{C}\right] \mathrm{DASB} 5$-HTT $\mathrm{BP}_{\mathrm{ND}}$ in the PFC and ACC of severe $\mathrm{SAD}$ cases relative to healthy volunteers (MannWhitney $U, U=42.5$ and 37.0, $p=0.005$ and 0.003, respectively, Figure 1 and Table 3), an effect also observed in other ROIs $(U=40.0-62.0, p=0.004-0.048$, Figure 1 and Table 3), excepting the midbrain for which seasonal $\% \Delta$ $\left[{ }^{11} \mathrm{C}\right] \mathrm{DASB} 5-\mathrm{HTT} \mathrm{BP}_{\mathrm{ND}}$ was significantly greater across all SAD participants relative to healthy volunteers $(U=96.0$, $p=0.005$; Figure 1 and Table 2). In contrast, seasonal $\% \Delta$ $\left[{ }^{11} \mathrm{C}\right] \mathrm{DASB}$ 5-HTT $\mathrm{BP}_{\mathrm{ND}}$ in moderate SAD subjects was similar to healthy individuals with no difference in any ROI (Mann-Whitney $U, \quad U=51.0-106.0, \quad p=0.07-0.96$; Figure 1 and Table 3). Seasonal $\% \Delta 5$-HTT $\mathrm{BP}_{\mathrm{ND}}$ was consistent within individuals across brain regions (Cronbach's alpha, $\alpha=0.89$ ).

Seasonal \% $\Delta\left[{ }^{11} \mathrm{C}\right]$ DASB 5 -HTT $\mathrm{BP}_{\mathrm{ND}}$ measured applying the SRTM2 was similar to that of the non-invasive Logan method (Pearson's correlation coefficient, $r=0.93-0.98$, $p<0.0001$, across regions) and yielded similarly consistent main results.

\section{Effect of SAD and Severity Category on $\Delta\left[{ }^{11} \mathrm{C}\right] \mathrm{DASB}$ 5-HTT BP $\mathbf{N D}_{\mathrm{ND}}$}

The effects of SAD and severity on $\Delta\left[{ }^{11} \mathrm{C}\right] \mathrm{DASB} 5$-HTT $\mathrm{BP}_{\mathrm{ND}}$ were consistent with those on $\% \Delta\left[{ }^{11} \mathrm{C}\right] \mathrm{DASB} 5$-HTT $\mathrm{BP}_{\mathrm{ND}}$. A main effect of group was observed on $\Delta\left[{ }^{11} \mathrm{C}\right] \mathrm{DASB}$ 5 -HTT $\mathrm{BP}_{\mathrm{ND}}$ in the PFC and ACC (Kruskal-Wallis $H$-test, $\chi_{(2)}^{2}=8.32, p=0.016$ and $\chi_{(2)}^{2}=9.00, p=0.01$, respectively) and across other ROIs $\left(\chi_{(2)}^{2}=6.45-10.56, p=0.005-0.04\right)$. These findings were similarly driven by increased $\Delta\left[{ }^{11} \mathrm{C}\right]$ DASB 5-HTT $\mathrm{BP}_{\mathrm{ND}}$ of severe SAD cases relative to healthy volunteers (Mann-Whitney $U, U=38.5-52.5, p=0.003-$ 0.018 ) with no difference in $\Delta\left[{ }^{11} \mathrm{C}\right] \mathrm{DASB} 5$-HTT $\mathrm{BP}_{\mathrm{ND}}$ values upon comparison of moderate $\mathrm{SAD}$ and healthy groups $(U=60.0-108.0, \quad p=0.16-0.91$, Supplementary Figure S2). In comparison with healthy and moderate SAD groups, mean regional $\left[{ }^{11} \mathrm{C}\right] \mathrm{DASB} 5$-HTT $\mathrm{BP}_{\mathrm{ND}}$ values of severe $\mathrm{SAD}$ cases were greater in fall-winter by $0-7.89 \%$ and lower in spring-summer by 11.47-20.83\%; however, these differences were not statistically significant (Kruskal-Wallis $H$-test, fall-winter: $\chi_{(2)}^{2}=0.01-1.59, p=0.45-0.99$; springsummer: $\quad \chi_{(2)}^{2}=1.61-5.11, \quad p=0.08-0.45$, Supplementary Table S5).

\section{Relationship of Symptoms to \% $\Delta\left[{ }^{11}\right.$ C]DASB 5 -HTT $\mathrm{BP}_{\mathrm{ND}}$}

In $\mathrm{SAD}$ participants, a positive correlation was also observed between magnitude of seasonal \% $\Delta\left[{ }^{11} \mathrm{C}\right]$ DASB 5-HTT $\mathrm{BP}_{\mathrm{ND}}$ and SAD severity, as measured by the SPAQ GSS 


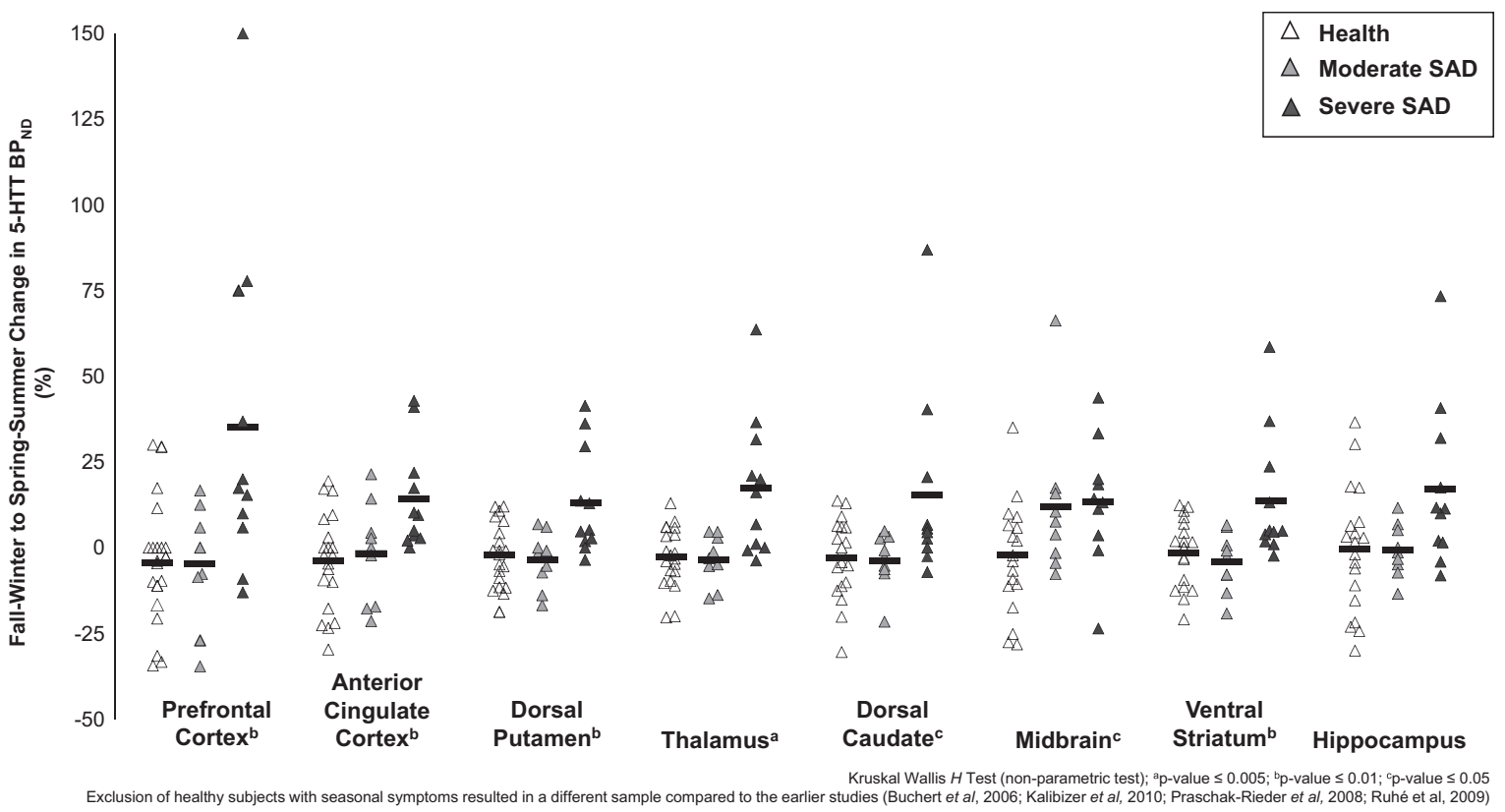

Figure I Seasonal percent change in serotonin transporter binding potential (\% $\Delta 5-\mathrm{HTT} \mathrm{BP}_{\mathrm{ND}}$ ) as measured in eight brain regions of interest (ROls).

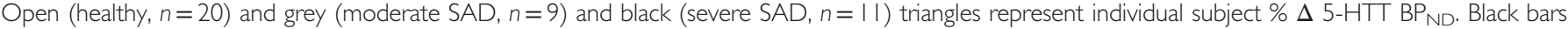
represent mean $\% \Delta 5-\mathrm{HTT} \mathrm{BP}_{\mathrm{ND}}$ for each group. \% $\Delta 5-\mathrm{HTT} \mathrm{BP}_{\mathrm{ND}}$ was significantly greater in the prefrontal and anterior cingulate cortices (severe $\mathrm{SAD}$ vs healthy; Mann-Whitney $U, U=42.5$ and 37.0, $p=0.005$ and 0.003 , respectively; greater magnitude in severe SAD of 35. I0\% and I4.23\%, respectively) with similar findings observed in other regions $(U=40.0-62.0, p=0.004-0.048$; greater magnitude in severe SAD of $13.16-17.49 \%)$. To compare groups, the Kruskal-Wallis $H$-test was also applied at each region of interest. ${ }^{a} p$-value $\leqslant 0.005 ;{ }^{b} p$-value $\leqslant 0.0$ I; ${ }^{c} p$-value $\leqslant 0.05$. Seasonal $\% \Delta 5$-HTT BP $\mathrm{ND}$ was consistent within individuals across brain regions (Cronbach's alpha, $\alpha=0.89$ ).

(Table 4), which was significant in the PFC (Spearman's rank correlation coefficient, $\rho=0.52, p=0.018$ ) and trend level in the ACC (Spearman's rank correlation coefficient, $\rho=0.42$, $p=0.07$ ). Similar relationships were observed in other examined brain regions $(\rho=0.44-0.55, p=0.012-0.055)$, with the exception of the midbrain, in which no significant correlation was observed $(\rho=0.25, p=0.29$; Table 4$)$. However, in healthy participants, for which the range in SPAQ GSS scores was narrow, no significant correlations were observed between seasonal \% $\Delta\left[{ }^{11} \mathrm{C}\right] \mathrm{DASB}$ 5-HTT $\mathrm{BP}_{\mathrm{ND}}$ and SPAQ GSS in any brain region $(\rho=-0.18-0.36$, $p=0.12-0.92$; Table 4). Correlations between SPAQ scores and $\Delta\left[{ }^{11} \mathrm{C}\right] \mathrm{DASB}$ 5-HTT BP ${ }_{\mathrm{ND}}$ in SAD and healthy groups were comparable to those of seasonal $\% \Delta\left[{ }^{11} \mathrm{C}\right] \mathrm{DASB}$ 5 -HTT $\mathrm{BP}_{\mathrm{ND}}$ in all examined brain regions (Supplementary Figure S3, Supplementary Table S6).

In $\mathrm{SAD}$, post hoc exploratory analyses comparing a breakdown of the GSS by mood, energy, and appetite clusters found that the strongest correlations between seasonal change in mood symptoms and seasonal $\% \Delta$ $\left[{ }^{11} \mathrm{C}\right] \mathrm{DASB} 5$-HTT $\mathrm{BP}_{\mathrm{ND}}$ occurred in the PFC $(\rho=0.53$, $p=0.015)$, dorsal putamen $(\rho=0.66, p=0.002)$, dorsal caudate $(\rho=0.62, p=0.004)$, ventral striatum $(\rho=0.63$, $p=0.003)$ and thalamus $(\rho=0.59, p=0.006$; Supplementary Table S6). In terms of seasonal changes in energy levels, the strongest correlations were also observed in the PFC $(\rho=0.52, \quad p=0.019)$, dorsal putamen $(\rho=0.70$, $p=0.001)$, dorsal caudate $(\rho=0.68, p=0.001)$, ventral striatum $(\rho=0.71, p<0.0001)$ and thalamus $(\rho=0.66$, $p=0.001$; Supplementary Table S7). Similar relationships were found between changes in appetitive behaviors and seasonal \% $\Delta\left[{ }^{11} \mathrm{C}\right] \mathrm{DASB} 5$-HTT $\mathrm{BP}_{\mathrm{ND}}$ with the strongest correlations observed in the $\operatorname{PFC}(\rho=0.50, p=0.024)$, thalamus $(\rho=0.54, p=0.014)$, dorsal putamen $(\rho=0.48$, $p=0.03)$, hippocampus $(\rho=0.48, p=0.033)$ and ventral striatum $(\rho=0.42, p=0.069$; Supplementary Table S7).

\section{DISCUSSION}

This is the first study to investigate seasonal change in $\left[{ }^{11} \mathrm{C}\right]$ DASB 5-HTT $\mathrm{BP}_{\mathrm{ND}}$ in SAD. Although greater seasonal variation of $\left[{ }^{11} \mathrm{C}\right] \mathrm{DASB} 5-\mathrm{HTT} \mathrm{BP}_{\mathrm{ND}}$ in SAD as compared to health was observed across most brain regions sampled, including the PFC and ACC, the strongest finding was a more pronounced seasonal fluctuation of $\left[{ }^{11} \mathrm{C}\right] \mathrm{DASB}$ 5-HTT $\mathrm{BP}_{\mathrm{ND}}$ in severe $\mathrm{SAD}$ across all brain regions relative to moderate $\mathrm{SAD}$ and asymptomatic healthy groups. These results indicate that 5 -HTT $\mathrm{BP}_{\mathrm{ND}}$, as measured with $\left[{ }^{11} \mathrm{C}\right]$ DASB PET, is detecting a brain phenotype of SAD and suggests new opportunities for applying this neuroimaging method in biomarker-based approaches to develop new strategies for both prevention and treatment.

Greater seasonal fluctuation of $\left[{ }^{11} \mathrm{C}\right] \mathrm{DASB}$ 5-HTT BP ${ }_{\mathrm{ND}}$ across all examined brain regions, including the $\mathrm{PFC}$ and ACC, has important implications for SAD pathophysiology, particularly in regards to severe SAD. $\left[{ }^{11} \mathrm{C}\right] \mathrm{DASB}$ has a strong preferential binding to 5-HTT on the cell surface where functional 5-HTT are located and the binding of $\left[{ }^{11} \mathrm{C}\right]$ DASB is insensitive to competition by endogenous serotonin as demonstrated by the lack of effect of physiologically tolerable serotonergic manipulations in humans, such as 
Table 3 Group Differences in Seasonal Change in 5-HTT BP ${ }_{N D}$ in Participants Undergoing [ ' I C]DASB PET in Spring-Summer and Fall-Winter

\begin{tabular}{|c|c|c|c|c|c|c|}
\hline \multirow[t]{3}{*}{ Brain region } & \multicolumn{2}{|c|}{$\begin{array}{c}\text { Kruskal- } \\
\text { Wallis H-test }\end{array}$} & \multicolumn{4}{|c|}{ Mann-Whitney U-test } \\
\hline & \multirow[b]{2}{*}{$\chi_{(2)}^{2}{ }^{c}$} & \multirow[b]{2}{*}{$p$-Value } & \multicolumn{2}{|c|}{$\begin{array}{l}\text { Moderate } \\
\text { SAD vs } \\
\text { Healthy }\end{array}$} & \multicolumn{2}{|c|}{$\begin{array}{l}\text { Severe SAD vs } \\
\text { Healthy }^{\text {b }}\end{array}$} \\
\hline & & & $U^{d}$ & $p$-Value & $U^{d}$ & $p$-Value \\
\hline Prefrontal cortex & 8.82 & 0.01 & 84.0 & 0.78 & 42.5 & 0.005 \\
\hline Anterior cingulate cortex & 9.62 & 0.008 & 77.0 & 0.54 & 37.0 & 0.003 \\
\hline Dorsal putamen & 10.09 & 0.006 & 100.0 & 0.64 & 40.0 & 0.004 \\
\hline Thalamus & 10.45 & 0.005 & 106.0 & 0.45 & 41.0 & 0.004 \\
\hline Dorsal caudate & 7.01 & 0.03 & 99.0 & 0.67 & 55.5 & 0.02 \\
\hline Ventral striatum & 8.84 & 0.01 & 106.0 & 0.45 & 48.0 & 0.01 \\
\hline Midbrain & 8.71 & 0.013 & 51.0 & 0.07 & 45.0 & 0.007 \\
\hline Hippocampus & 5.26 & 0.07 & 91.0 & 0.96 & 62.0 & 0.048 \\
\hline
\end{tabular}

5-HTT BP ${ }_{N D}$, serotonin transporter binding potential (non-displaceable); KruskalWallis $H$, non-parametric test; Mann-Whitney $U$, non-parametric equivalent of an independent samples $t$-test.

$a_{n}=9$ (Moderate SAD) vs $n=20$ (Healthy).

$b_{n}=1 \mid$ (Severe SAD) vs $n=20$ (Healthy).

'Kruskal-Wallis test statistic

dMann-Whitney U-test statistic.

acute tryptophan depletion (Praschak-Rieder et al, 2005; Quelch et al, 2012; Talbot et al, 2005). As such, the changes in 5 -HTT $\mathrm{BP}_{\mathrm{ND}}$ observed in vivo using $\left[{ }^{11} \mathrm{C}\right] \mathrm{DASB}$ PET reflect greater availability of the 5-HTT to clear serotonin from extracellular space in the winter, thereby lowering levels of extracellular serotonin. This is a key issue, given that overexpression of 5-HTT in the PFC is associated with decreased stimulation-induced release of 5-HT from serotonergic neurons and differential expression of the 5-HTT is associated with magnitude of response to anxiogenic stimuli (Jennings et al, 2010; Lesch et al, 1996; Mouri et al, 2012). In addition, while greater seasonal variation in $\left[{ }^{11} \mathrm{C}\right] \mathrm{DASB}$ 5-HTT $\mathrm{BP}_{\mathrm{ND}}$ was observed in severe $\mathrm{SAD}$ relative to health, $\left[{ }^{11} \mathrm{C}\right] \mathrm{DASB} 5-\mathrm{HTT} \mathrm{BP}_{\mathrm{ND}}$ values did not differ across groups in summer and winter seasons, suggesting that, in SAD, change across seasons is more relevant than the $\left[{ }^{11} \mathrm{C}\right] \mathrm{DASB}$ 5-HTT $\mathrm{BP}_{\mathrm{ND}}$ levels, themselves. Taken together, these findings suggest that across the shift from summer to winter, seasonal change in 5-HTT levels and/or affinity may alter the dynamics of extracellular 5-HT release within the PFC, ACC, and subcortical structures thereby dysregulating systems adversely affected in severe SAD, including mood, energy, and appetite.

Identifying a new brain biomarker in SAD is critical for therapeutic advances because brain biomarkers are an essential guide for developing treatments of complex neuropsychiatric illnesses with multiple phenotypes. Although it is well accepted that novel therapeutics require target engagement, it is a newer direction in therapeutic development to assess the effects of treatment on the target biomarker itself. Knowledge that the biomarker has been engaged then allows for assessment of whether an adequate
Table 4 Correlations Between Seasonal Change in 5-HTT BP ${ }_{N D}$ and Seasonal Pattern Assessment Questionnaire Global Seasonality Score

\begin{tabular}{lcccccc}
\hline Brain region & \multicolumn{2}{c}{ SAD $(\boldsymbol{n}=\mathbf{2 0})$} & & \multicolumn{2}{c}{ Healthy $(\boldsymbol{n}=\mathbf{2 0})$} \\
\cline { 2 - 3 } \cline { 6 - 7 } & $\rho^{\mathbf{a}}$ & $\mathbf{p}$-Value & & $\rho^{\mathbf{a}}$ & $\boldsymbol{p}$-Value \\
\hline Prefrontal cortex & 0.52 & 0.018 & & 0.21 & 0.38 \\
Anterior cingulate cortex & 0.42 & 0.07 & & 0.20 & 0.39 \\
Dorsal putamen & 0.55 & 0.012 & & 0.08 & 0.74 \\
Thalamus & 0.54 & 0.014 & & 0.11 & 0.65 \\
Dorsal caudate & 0.46 & 0.04 & & 0.36 & 0.12 \\
Ventral striatum & 0.51 & 0.02 & & 0.12 & 0.60 \\
Midbrain & 0.25 & 0.29 & & -0.18 & 0.44 \\
Hippocampus & 0.44 & 0.055 & & 0.03 & 0.92 \\
\hline
\end{tabular}

aSpearman's rank correlation coefficient.

number of phenotypes have been targeted in clinical trials with symptom burden as the primary outcome. In the present investigation, the biomarker identified provides opportunities to create novel prevention methods for SAD: it is clear that the environmental combination of seasonal variables, including light, temperature, and humidity, influence $\left[{ }^{11} \mathrm{C}\right] \mathrm{DASB}$ 5-HTT $\mathrm{BP}_{\mathrm{ND}}$ in those with severe SAD. Future studies could identify combinations of specific environmental factors and their exposure thresholds that induce seasonal change in $\left[{ }^{11} \mathrm{C}\right] \mathrm{DASB} 5-\mathrm{HTT} \mathrm{BP}_{\mathrm{ND}}$ so that by staying below such thresholds or adding other preventative interventions, such as light therapy, the winter elevation in $\left[{ }^{11} \mathrm{C}\right] \mathrm{DASB} 5$-HTT BP $\mathrm{ND}$ could be avoided. Avoidance of environmental qualities and exposure thresholds that induce seasonal fluctuations in $\left[{ }^{11} \mathrm{C}\right] \mathrm{DASB} 5$-HTT $\mathrm{BP} \mathrm{ND}_{\mathrm{ND}}$ could then be incorporated into larger scale clinical studies as prevention strategies in high-risk communities, such as those in Northern latitudes where SAD prevalence exceeds $6 \%$ (Magnusson, 2000).

There are some limitations of this study typical of SAD investigations and human brain studies of neuropsychiatric disease. First, it was not always possible to scan SAD participants when their winter MDE was at its most severe. As such, completion of winter scanning before the symptomatic nadir may have underestimated the strength of the relationship between severity of SAD and seasonal $\% \Delta\left[{ }^{11} \mathrm{C}\right]$ DASB 5-HTT BP ${ }_{\mathrm{ND}}$. Second, exposure to different seasonal environmental influences are highly inter-correlated and does not allow for the differentiation of their individual effects. Third, while $\left[{ }^{11} \mathrm{C}\right] \mathrm{DASB}$ has strong preferential binding to 5 -HTT on outer cell membranes, 5-HTT $\mathrm{BP}_{\mathrm{ND}}$ is a measure of both 5-HTT density and its affinity for $\left[{ }^{11} \mathrm{C}\right]$ DASB (Quelch et al, 2012). Thus, it is not possible to differentiate between changes in 5-HTT density and affinity, although it would be expected that when the affinity of the serotonin transporter is altered there is a similar functional effect on the dynamics of extracellular serotonin concentrations. Finally, as our approach was to determine whether the severity of SAD was related to seasonal change in $\left[{ }^{11} \mathrm{C}\right] \mathrm{DASB}$ 5-HTT $\mathrm{BP}_{\mathrm{ND}}$, we deliberately chose healthy volunteers with negligible severity of seasonal symptoms for comparison 
with SAD subjects with more extreme symptoms, and this may have reduced our ability to detect seasonal differences in healthy subjects (see Supplementary Discussion for further explanation). Since $25 \%$ of healthy people experience seasonal variation in mood symptoms, an additional interesting future direction would be to assess \% $\Delta\left[{ }^{11} \mathrm{C}\right]$ DASB 5-HTT $\mathrm{BP}_{\mathrm{ND}}$ in a group of healthy subjects with substantial seasonality to further characterize this brain phenotype (Kasper et al, 1989).

In summary, this is the first investigation to compare seasonal variation in $\left[{ }^{11} \mathrm{C}\right] \mathrm{DASB}$-HTT $\mathrm{BP}_{\mathrm{ND}}$ in SAD participants, across a spectrum of illness severity, to a group of healthy volunteers, asymptomatic for seasonal changes in mood and behavior. The primary finding is that, across brain regions sampled, including the PFC and ACC, $\left[{ }^{11} \mathrm{C}\right] \mathrm{DASB}$ 5-HTT $\mathrm{BP}_{\mathrm{ND}}$ was significantly elevated in winter as compared to summer in SAD, particularly in severe SAD. Given that $\left[{ }^{11} \mathrm{C}\right] \mathrm{DASB}$ binds preferentially to the 5-HTT on the cell surface, this has important pathophysiological implications for the dynamics of serotonin release and is best interpreted as reflecting a key phenotype of SAD (Quelch et al, 2012). As a brain biomarker, greater seasonal $\%$ change in $\left[{ }^{11} \mathrm{C}\right] \mathrm{DASB}$-HTT $\mathrm{BP}_{\mathrm{ND}}$ is an important breakthrough because it can be applied to develop interventions to reduce environmental impact on this target and create very specific prevention strategies for SAD.

\section{FUNDING AND DISCLOSURE}

Drs Meyer, Wilson, and Houle have received operating grant funding for other studies from Eli Lilly, GlaxoSmithKline, Bristol-Myers Squibb, Lundbeck, SK Life Science and Johnson and Johnson in the past 5 years. With the exception of Johnson and Johnson, Dr Meyer has consulted to these companies, as well as Sepracor, Trius Therapeutics, and Mylan. None of these companies participated in the funding, design, or execution of this study or writing the manuscript. Dr Meyer is developing natural health products to treat highrisk states for MDE. Dr Meyer is applying for patents to implement measures utilizing MAO to diagnose or treat mood disorders and to use peripheral measures as surrogate measures for brain inflammation.

\section{ACKNOWLEDGMENTS}

This research received project support from the Canadian Institutes of Health Research (CIHR) (grant number: RN158849-274056) and student salary support from Brain Canada. We thank the Campbell Family Mental Health Research Institute; technicians Alvina Ng, Laura Nguyen, Anusha Ravichandran and Hillary Bruce; chemistry staff Armando Garcia, Winston Stableford, and Min Wong; and engineers Terry Bell and Ted Harris-Brandts for their assistance with this project.

\section{REFERENCES}

Bartko JJ, Kasper S (1989). Seasonal changes in mood and behavior: a cluster analytic approach. Psychiatry Res 28: 227-239.

Buchert R, Schulze O, Wilke F, Berding G, Thomasius R, Petersen K et al (2006). Is correction for age necessary in SPECT or PET of the central serotonin transporter in young, healthy adults? J Nucl Med 47: 38-42.

Caspi A, Hariri AR, Holmes A, Uher R, Moffitt TE (2010). Genetic sensitivity to the environment: the case of the serotonin transporter gene and its implications for studying complex diseases and traits. Am J Psychiatry 167: 509-527.

Chiuccariello L, Houle S, Miler L, Cooke RG, Rusjan PM, Rajkowska G, Levitan RD et al (2014). Elevated monoamine oxidase a binding during major depressive episodes is associated with greater severity and reversed neurovegetative symptoms. Neuropsychopharmacology 39: 973-980.

Deschwanden A, Karolewicz B, Feyissa AM, Treyer V, Ametamey SM, Johayem A et al (2011). Reduced metabotropic glutamate receptor 5 density in major depression determined by [(11)C]ABP688 PET and postmortem study. Am J Psychiatry 168: 727-734.

Eisenberg DP, Kohn PD, Baller EB, Bronstein JA, Masdeu JC, Berman KF (2010). Seasonal effects on human striatal presynaptic dopamine synthesis. J Neurosci 30: 14691-14694.

Faedda GL, Tondo L, Teicher MH, Baldessarini RJ, Gelbard HA, Floris GF (1993). Seasonal mood disorders. Patterns of seasonal recurrence in mania and depression. Arch Gen Psychiatry 50: $17-23$.

Fujita M, Hines CS, Zoghbi SS, Mallinger AG, Dickstein LP, Liow JS et al (2012). Downregulation of brain phosphodiesterase type IV measured with 11C-(R)-rolipram positron emission tomography in major depressive disorder. Biol Psychiatry 72: 548-554.

Ginovart N, Wilson AA, Meyer JH, Hussey D, Houle S (2001). Positron emission tomography quantification of $\left[{ }^{11} \mathrm{C}\right]-\mathrm{DASB}$ binding to the human serotonin transporter: modeling strategies. J Cereb Blood Flow Metab 21: 1342-1353.

Harmer CJ, Shelley NC, Cowen PJ, Goodwin GM (2004). Increased positive versus negative affective perception and memory in healthy volunteers following selective serotonin and norepinephrine reuptake inhibition. Am J Psychiatry 161: 1256-1263.

Harrison SJ, Tyrer AE, Levitan RD, Xu X, Houle S, Wilson AA et al (2015). Light therapy and serotonin transporter binding in the anterior cingulate and prefrontal cortex. Acta Psychiatr Scand 132: 379-388.

Ichise M, Liow JS, Lu JQ, Takano A, Model K, Toyama H et al (2003). Linearized reference tissue parametric imaging methods: application to $\left[{ }^{11} \mathrm{C}\right] \mathrm{DASB}$ positron emission tomography studies of the serotonin transporter in human brain. J Cereb Blood Flow Metab 23: 1096-1112.

Jennings KA, Lesch KP, Sharp T, Cragg SJ (2010). Non-linear relationship between 5-HT transporter gene expression and frequency sensitivity of 5-HT signals. J Neurochem 115: 965-973.

Johansson C, Willeit M, Smedh C, Ekholm J, Paunio T, Kieseppä T et al (2003). Circadian clock-related polymorphisms in seasonal affective disorder and their relevance to diurnal preference. Neuropsychopharmacology 28: 734-739.

Kalbitzer J, Erritzoe D, Holst KK, Nielsen FA, Marner L, Lehel S et al (2010). Seasonal changes in brain serotonin transporter binding in short serotonin transporter linked polymorphic region-allele carriers but not in long-allele homozygotes. Biol Psychiatry 67: 1033-1039.

Kasper S, Wehr TA, Bartko JJ, Gaist PA, Rosenthal NE (1989). Epidemiological findings of seasonal changes in mood and behavior. A telephone survey of Montgomery County, Maryland. Arch Gen Psychiatry 46: 823-833.

Lam RW, Levitt AJ, Levitan RD, Enns MW, Morehouse R, Michalak EE et al (2006). The Can-SAD study: a randomized controlled trial of the effectiveness of light therapy and fluoxetine in patients with winter seasonal affective disorder. Am J Psychiatry 163: 805-812. 
Lambert GW, Reid C, Kaye DM, Jennings GL, Esler MD (2002). Effect of sunlight and season on serotonin turnover in the brain. Lancet 360: 1840-1842.

Lavoie MP, Lam RW, Bouchard G, Sasseville A, Charron MC, Gagné AM et al (2009). Evidence of a biological effect of light therapy on the retina of patients with seasonal affective disorder. Biol Psychiatry 66: 253-258.

Lesch KP, Bengel D, Heils A, Sabol SZ, Greenberg BD, Petri S et al (1996). Association of anxiety-related traits with a polymorphism in the serotonin transporter gene regulatory region. Science 274: 1527-1531.

Levitan RD, Kaplan AS, Brown GM, Vaccarino FJ, Kennedy SH, Levitt AJ et al (1998). Hormonal and subjective responses to intravenous $\mathrm{m}$-chlorophenylpiperazine in women with seasonal affective disorder. Arch Gen Psychiatry 55: 244-249.

Levitan RD, Masellis M, Lam RW, Kaplan AS, Davis C, Tharmalingam S et al (2006). A birth-season/DRD4 gene interaction predicts weight gain and obesity in women with seasonal affective disorder: a seasonal thrifty phenotype hypothesis. Neuropsychopharmacology 31: 2498-2503.

Line SJ, Barkus C, Rawlings N, Jennings K, McHugh S, Sharp T et al (2014). Reduced sensitivity to both positive and negative reinforcement in mice over-expressing the 5-hydroxytryptamine transporter. Eur J Neurosci 40: 3735-3745.

Logan J, Fowler JS, Volkow ND, Wang GJ, Ding YS, Alexoff DL (1996). Distribution volume ratios without blood sampling from graphical analysis of PET data. J Cereb Blood Flow Metab 16: 834-840.

Magnusson A (2000). An overview of epidemiological studies on seasonal affective disorder. Acta Psychiatr Scand 101: 176-184.

Meyer JH (2012). Neuroimaging markers of cellular function in major depressive disorder: implications for therapeutics, personalized medicine, and prevention. Clin Pharmacol Ther 91: 201-214.

Meyer JH, McMain S, Kennedy SH, Korman L, Brown GM, DaSilva JN et al (2003). Dysfunctional attitudes and 5-HT2 receptors during depression and self-harm. Am J Psychiatry 160: 90-99.

Meyer JH, Wilson AA, Sagrati S, Miler L, Rusjan P, Bloomfield PM et al (2009). Brain monoamine oxidase A binding in major depressive disorder: relationship to selective serotonin reuptake inhibitor treatment, recovery, and recurrence. Arch Gen Psychiatry 66: 1304-1312.

Modell JG, Rosenthal NE, Harriett AE, Krishen A, Asgharian A, Foster VJ et al (2005). Seasonal affective disorder and its prevention by anticipatory treatment with bupropion XL. Biol Psychiatry 58: 658-667.

Mouri A, Sasaki A, Watanabe K, Sogawa C, Kitayama S, Mamiya T et al (2012). MAGE-D1 regulates expression of depression-like behavior through serotonin transporter ubiquitylation. J Neurosci 32: 4562-4580.

Praschak-Rieder N, Willeit M, Wilson AA, Houle S, Meyer JH (2008). Seasonal variation in human brain serotonin transporter binding. Arch Gen Psychiatry 65: 1072-1078.

Praschak-Rieder N, Wilson AA, Hussey D, Carella A, Wei C, Ginovart N et al (2005). Effects of tryptophan depletion on the serotonin transporter in healthy humans. Biol Psychiatry 58: 825-830.

Quelch DR, Parker CA, Nutt DJ, Tyacke RJ, Erritzoe D (2012). Influence of different cellular environments on $\left[{ }^{3} \mathrm{H}\right] \mathrm{DASB}$ radioligand binding. Synapse 66: 1035-1039.
Ressler KJ, Mayberg HS (2007). Targeting abnormal neural circuits in mood and anxiety disorders: from the laboratory to the clinic. Nat Neurosci 10: 1116-1124.

Rohan KJ, Nillni YI, Mahon JN, Roecklein KA, Sitnikov L, Haaga DA (2011). Cognitive vulnerability in moderate, mild, and low seasonality. J Nerv Ment Dis 199: 961-970.

Rosenthal NE, Sack DA, Gillin JC, Lewy AJ, Goodwin FK, Davenport $Y$ et al (1984a). Seasonal affective disorder: a description of the syndrome and preliminary findings with light therapy. Arch Gen Psychiatry 41: 72-80.

Rosenthal N, Bradt G, Wehr T (1984b). Seasonal Pattern Assessment Questionnaire (SPAQ). National Institute of Mental Health: Bethesda, MD, USA.

Ruhé HG, Booij J, Reitsma JB, Schene AH (2009). Serotonin transporter binding with $\left[{ }^{123} \mathrm{I}\right]$ beta-CIT SPECT in major depressive disorder versus controls: effect of season and gender. Eur J Nucl Med Mol Imaging 36: 841-849.

Rusjan P, Mamo D, Ginovart N, Hussey D, Vitcu I, Yasuno F et al (2006). An automated method for the extraction of regional data from PET images. Psychiatry Res 147: 79-89.

Sanacora G, Gueorguieva R, Epperson CN, Wu YT, Appel M, Rothman DL et al (2004). Subtype-specific alterations of gammaaminobutyric acid and glutamate in patients with major depression. Arch Gen Psychiatry 61: 705-713.

Schwartz PJ, Brown C, Wehr TA, Rosenthal NE (1996). Winter seasonal affective disorder: a follow-up study of the first 59 patients of the National Institute of Mental Health Seasonal Studies Program. Am J Psychiatry 153: 1028-1036.

Schwartz PJ, Murphy DL, Wehr TA, Garcia-Borreguero D, Oren DA, Moul DE et al (1997). Effects of meta-chlorophenylpiperazine infusions in patients with seasonal affective disorder and healthy control subjects. Diurnal responses and nocturnal regulatory mechanisms. Arch Gen Psychiatry 54: 375-385.

Setiawan E, Wilson AA, Mizrahi R, Rusjan PM, Miler L, Rajkowska G et al (2015). Role of translocator protein density, a marker of neuroinflammation, in the brain during major depressive episodes. JAMA Psychiatry 72: 268-275.

Spindelegger C, Stein P, Wadsak W, Fink M, Mitterhauser M, Moser $U$ et al (2012). Light-dependent alteration of serotonin-1A receptor binding in cortical and subcortical limbic regions in the human brain. World J Biol Psychiatry 13: 413-422.

Talbot PS, Frankle WG, Hwang DR, Huang Y, Suckow RF, Slifstein $M$ et al (2005). Effects of reduced endogenous 5 -HT on the in vivo binding of the serotonin transporter radioligand 11C-DASB in healthy humans. Synapse 55: 164-175.

Wehr TA, Duncan WC Jr, Sher L, Aeschbach D, Schwartz PJ, Turner EH et al (2001). A circadian signal of change of season in patients with seasonal affective disorder. Arch Gen Psychiatry 58: $1108-1114$.

Wilson A, Schmidt M, Ginovart N, Meyer J, Houle S (2000). Novel radiotracers for imaging the serotonin transporter by positron emission tomography: synthesis, radiosynthesis, in vitro and ex vivo evaluation of $\left[{ }^{11} \mathrm{C}\right]$-labelled 2-(Phenylthio) araalkylamines. J Med Chem 43: 3103-3110.

$\mathrm{Wu}$ Y, Carson RE (2002). Noise reduction in the simplified reference tissue model for neuroreceptor functional imaging. J Cereb Blood Flow Metab 22: 1440-1452.

Supplementary Information accompanies the paper on the Neuropsychopharmacology website (http://www.nature.com/npp) 